\title{
Profile of Multi Drug Resistant Tuberculosis patients: A Study at Drug Resistant Tuberculosis Centre in Kumaun Region, Uttarakhand
}

\section{Sadhana Awasthi ${ }^{1}$, Neha Verma ${ }^{2}$, Ram Gopal Nautiyal ${ }^{3}$, Hariom Kumar Solanki ${ }^{4}$}

${ }^{1}$ Associate Professor and Head, Department of Community Medicine, Government Medical College, Haldwani, Uttarakhand, India; ${ }^{2}$ Senior Resident, Department of Community and Family Medicine, All India Institute of Medical Sciences, Rishikesh, Uttarakhand, India; ${ }^{3}$ Principal and Professor, Department of Respiratory Medicine , S.S.J. Government Institute of Medical Sciences \& Research, Almora, Uttarakhand, India; ${ }^{4}$ Assistant Professor, Department of Community Medicine, Government Institute of Medical Sciences, Greater Noida, GB Nagar, Uttar Pradesh, India

\begin{tabular}{|c|c|c|c|c|c|c|c|c|}
\hline Abstract & Introduction & Methodology & Results & Conclusion & References & Citation & \multicolumn{2}{|c|}{ Tables / Figures } \\
\hline \multicolumn{9}{|c|}{ Corresponding Author } \\
\hline \multicolumn{8}{|c|}{$\begin{array}{l}\text { Dr. Neha Verma, Senior Resident, Department of Community and Family Medicine, All India } \\
\text { Institute of Medical Sciences Rishikesh, Uttarakhand } \\
\text { E Mail ID: neha88sunshine@gmail.com }\end{array}$} & 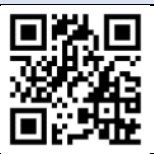 \\
\hline
\end{tabular}

\section{Citation}

Awasthi S, Verma N, Nautiyal RG, Solanki HK. Profile of Multi Drug Resistant Tuberculosis patients: A Study at Drug Resistant Tuberculosis Centre in Kumaun Region, Uttarakhand. Indian J Comm Health. 2020;32(4):647652. https://doi.org/10.47203/IJCH.2020.v32i04.007

Source of Funding: Nil Conflict of Interest: None declared

\section{Article Cycle}

Received: 24/07/2020; Revision: 13/09/2020; Accepted: 05/10/2020; Published: 31/12/2020 This work is licensed under a Creative Commons Attribution 4.0 International License.

\section{Abstract}

Background: Drug Resistant Tuberculosis (DR-TB) has frequently been encountered in India, and its presence has been known virtually from the time anti-TB drugs were introduced for the treatment of Tuberculosis. Multi Drug Resistant Tuberculosis (MDR-TB) is a man-made phenomenon and has become a formidable challenge to effective Tuberculosis control in India. Objectives: To study the Socio-demographic and Clinical profile of Multi Drug Resistant Tuberculosis (MDR-TB) patients presenting to Drug Resistant Tuberculosis (DR-TB) Centre at Govt. Medical College, Haldwani in the Kumaun region, Uttarakhand. Methodology: This study is a Record based study, where in service data available at Drug Resistant Tuberculosis (DR-TB) Centre at Govt. Medical College, Haldwani in the Kumaun region, Uttarakhand, was accessed and analyzed. Inclusion criteria included all patients with diagnosis of Multi Drug Resistant Tuberculosis (MDR-TB) presenting to the centre from 1st April 2015 to 31st December 2015. Results: The present study showed that younger age group particularly males were more affected with MDR-TB. Under-nutrition was quite prevalent among the MDR-TB patients. $56.7 \%$ cases were addicted to alcohol and $54.3 \%$ cases were addicted to smoking. $85.8 \%$ patients took treatment for TB and $44.1 \%$ not completed their treatment. Relapse of previous anti-tuberculosis treatment was found to be the major contributor in MDR-TB suspect cases. Prevalence of XDR-TB was also found to be low. Conclusion: The findings of the study emphasize the importance of studying the socio-demographic factors and baseline clinical characteristics in different MDR-TB patient categories to timely modify and strengthen the national programs.

\section{Keywords}

Drug Resistant Tuberculosis (DR-TB) Centre; Multi Drug Resistant Tuberculosis (MDR-TB).

\section{Introduction}

Tuberculosis (TB) is as ancient as the mankind (1). Emergence of drug resistant Mycobacterium tuberculosis (TB), particularly multi drug resistant tuberculosis (MDR-TB) and more recently extensively drug resistant tuberculosis (XDR-TB) is 
becoming a major public health problem and is posing a threat to global efforts of TB control (2). In 2015 , there were an estimated 480000 new cases of MDR-TB, additional 100000 people with Rifampicin resistant TB (RR-TB) cases worldwide, and approximately 250000 deaths from MDR-TB. Highest levels of MDR-TB were reported from Eastern European and central Asian countries (3).

India accounts for 1/4th of global TB burden. According to the latest WHO Global Tuberculosis Report released in 2016, India has highest burden of both TB and MDR-TB. An estimated 1.3 lakh incident MDR TB patients emerge annually in India which include 79000 MDR-TB patients estimates among notified pulmonary cases (4).

Mismanagement of MDR-TB with irrational use of second line drugs may lead to development of XDRTB. Worldwide, XDR-TB, contributes $9.5 \%$ of MDR-TB patients' cases as reported by WHO in 2015. The notified cases of XDR-TB by World Health Organization (WHO) region for 2016 were 8,014. According to data reported on XDR-TB from India, varied from $0.3 \%$ to $60 \%$ of MDR (5).

The HIV-TB co-infection has been aptly described as "cursed duet" (6). According to WHO, India bears second highest number of estimated HIV associated TB in the world. An estimated 1.1 lakh HIV associated TB occurred in 2015 and 37,000 estimated number of patients died among them(7).

India began services for diagnostic and treatment services for multi-drug resistant TB (MDR-TB) in 2007 and achieved complete coverage in 2013. Till 2016, 1,39,369 persons with MDR-TB/ RR TB diagnosed and $1,26,136(91 \%)$ patients were put on treatment under RNTCP (8).

\section{Aims \& Objectives}

To study the Socio-demographic and Clinical profile of Multi Drug Resistant Tuberculosis (MDR-TB) patients.

\section{Material \& Methods}

This is a record-based study of MDR-TB patients where in-service data available at a Drug Resistant Tuberculosis (DR-TB) center at Government Medical College, Haldwani in Kumaon region, Uttarakhand was accessed and analyzed. It manages MDR-TB patients who come from different parts of Kumaon region. All patients who were admitted in drug resistant tuberculosis center (DR-TB center) for initiation of DOTS Plus between 1st April 2015 to 31st March 2016 were included in the study. Ethical clearance was obtained before conducting study from Institutional Ethical Committee of Government Medical college, Haldwani.

Setting: In Nainital district there are 8 Tuberculosis Unit, namely Haldwani, Ramnagar, Padampuri, Bhowali, Kotabagh, Motahaldu, Okhalkhanda and Betalghat. These TU are under the supervision of medical officer tuberculosis control (MOTC). The chief tuberculosis officer (СTO) is in overall charge of the RNTCP programme in the district. The Nainital district refer sputum samples of suspected MDR-TB cases to the Intermediate Reference Laboratory (IRL) in Dehradun, for culture and drug sensitivity testing (DST). Three diagnostic technologies are used: Cartridge-Based Nucleic Acid Amplification Testing (CBNAAT), Line Probe Assay (LPA), Mycobacterial Growth Indicator Tube (MGIT) method. After confirmation of MDR-TB, patient is referred to the drug resistant tuberculosis center (DR-TB center) for initiation of regimen for MDR-TB. The Department of Respiratory Medicine of Sushila Tiwari Memorial Hospital in Haldwani is the designated DR-TB center of Kumaon. At the time of starting DOTS Plus detailed history was taken including screening for drug or alcohol abuse. Weight and height were measured. Routine investigations like complete blood count with platelets, blood sugar to screen for Diabetes Mellitus, liver function tests, blood urea and creatinine to assess the kidney function, thyroid profile, screening for HIV at Integrated Counselling and Testing Center and chest X-ray were done at baseline. Cases with extra-pulmonary TB (EPTB) were subjected to tissue biopsy and culture DST.

\section{Definitions (9)}

MDR-TB Case: A TB patient whose sputum is culture positive for Mycobacterium tuberculosis and is resistant in-vitro to isoniazid and rifampicin with or without other anti-tubercular drugs based on DST results from an RNTCP-certified Culture \& DST Laboratory

XDR-TB Case: An MDR TB case whose recovered M. tuberculosis isolate is resistant to at least isoniazid, rifampicin, a fluoroquinolone (ofloxacin, levofloxacin, or moxifloxacin) and a second line injectable anti TB drug (kanamycin, amikacin, or capreomycin) at a RNTCP-certified Culture \& DST Laboratory.

MDR suspect category: A patient suspected of drugresistant tuberculosis, based on RNTCP criteria for 
submission of specimens for drug-susceptibility

testing.

\section{Criteria A}

- All failures of new TB cases

- Smear +ve previously treated cases who remain smear + ve at 4th month onwards

- All pulmonary TB cases who are contacts of known MDR TB case

Criteria B - in addition to Criteria A:

- All smear +ve previously treated pulmonary TB cases at diagnosis

- Any smear +ve follow up result in new or previously treated cases

Criteria $\mathbf{C}$ - in addition to Criteria B

- All smear -ve previously treated pulmonary TB cases at diagnosis,

- HIV TB co-infected cases at diagnosis

Data Collection and analysis: This is a secondary data analysis study. The data included was collected from the documents and registers maintained at DRTB center for each admitted MDR TB patient. The data was collected using a structured proforma. The proforma was divided into two parts. The first part consists of questions on socio-demographic profile and second part consists of baseline clinical characteristics of MDR -TB patients. The data was coded and entered in Microsoft excel. Analysis was done using SPSS version 21 and descriptive interpretation of data was done in the form of percentages. Independent $t$ test was used to compare mean age of females to males.

\section{Results}

[Table 1] showed that maximum MDR-TB patients were in the age group of 21-30 years. (mean age = 36.28 years, standard deviation (SD) 13.97 years; range 11 - 70 years). The male to female ratio was 2.8:1 Majority of them were males (74.1\%), hindu $(86.6 \%)$, married $(72.4 \%)$, educated upto 5 th class (35.4\%), living in joint family (67.7\%) in rural areas $(55.9 \%)$ and were of service class (19.7\%). 56.7\% addicted to alcohol and $45.7 \%$ to smoking.

[Table 2] shows the distribution of MDR-TB cases according to their baseline characteristics. According to MDR-TB categories majority of patients belongs to Category B (81.9\%) followed by category A (18.1\%). Diabetes (84\%) was the commonest co-morbidity among the study group.

$0.8 \%$ Patients was HIV positive, though HIV status was not checked in $3.9 \%$ cases. $75.6 \%$ Patients were undernourished with BMI less than $18.5 \mathrm{Kg} / \mathrm{m} 2$.
Pulmonary TB was present in $100 \%$ patients. On chest X-Ray bilateral lesions (95.3\%) was more common than unilateral lesions (4.7\%).

Fever was the most common symptom occurring in $95.3 \%$ patients followed by cough with expectoration (92.1\%), loss of appetite and weight $(89.8 \%)$ and shortness of breath (37.1\%).

Majority (85.8\%) of patients had previously taken treatment for TB and $44.1 \%$ did not complete their treatment.

Outcome-wise $95.3 \%$ patients were under treatment and $4.7 \%$ patients had been expired.

\section{Discussion}

Drug resistance is not a new phenomenon in India. It has been reported even much before the era of RNTCP (10).

However, high level of resistance to second line drugs (SLD) including XDR-TB as shown in many recent studies across the country has generated concern $(11,12,13,14)$.

In the present study majority of the MDR-TB cases (34.5\%) were in the younger age group (21-30 years); mean age was 36.28 years. In a retrospective study done in a TB unit in Mumbai, Dholakia and Shah noted that majority of the cases $(67.6 \%)$ were in the age group 15-35 years with a mean age of 31years (15). Udwadia et al, Sharma et al and Mukherjee et al. also reported prevalence of younger age group among MDR-TB patients with the mean age of their study groups being 29.7 years, 33.25 years and 32.52 years respectively $(14,16)$. Majority of our cases were male (74.1\%). Male predominance among MDR-TB cases has been also reported by other authors $(13,17,18)$.

The occupational profile of our patients revealed that a majority of them were in service followed by household workers, skilled workers, student, labour. However, Mukherjee et al. observed a significantly higher prevalence of pulmonary TB in among household workers, followed by labourers and skilled workers (18).

In our study majority of patients belonged to category B (81.9\%). A meta-analysis also showed that relapse rate is high (almost $10 \%$ ) in India and the risk factors for relapse included drug irregularity, initial drug resistance, smoking, and alcoholism (19). However, in a prospective study conducted by Sethiet al. in North India major proportion of MDRTB cases was due to treatment failure (20). 
The mean BMI of the patients in this study was 18.5 $\mathrm{kg} / \mathrm{m} 2,75.6 \%$ were undernourished. Undernutrition among MDR-TB cases was also reported from another studies $(18,16)$.

The commonest comorbidity among our study group was Diabetes Mellitus (84\%). However, Mukherjii et al, Datta et al.(18) found COPD to be the commonest comorbid disease among MDR-TB cases in a tertiary care hospital of Kolkata and Kashmir respectively. COPD was present as a comorbid illness among $17.44 \%$ participants in their study whereas in the present study only $4 \%$ patients had COPD.

Globally, MDR-TB has been a particular concern among HIV-infected persons, whose rate of survival is substantially lower than that of those not infected, $(21,22,23)$ and testing for HIV is recommended for all TB patients. The literature regarding prevalence of HIV in MDR-TB is scanty from most parts of India. Datta et al (13) and Mukherjee et al (18) reported 1.9\% and $2.90 \%$ HIV seropositivity among MDR -TB cases. However, in the present study $0.8 \%$ MDR-TB patients were found to be HIV seropositive.

All patients in our study had pulmonary TB (100\%) (15). Radiologically our patients usually had bilateral (95.3\%). This has also been reported by some other Indian observers $(14,15)$. Worldwide, the prevalence of XDR-TB is on the rise. The proportion of MDR-TB cases with XDR-TB was highest in Georgia (20.0\%) (24). Among our study group, 3.9\% patients were found to have XDR-TB. This figure is almost consistent with published reports from various other parts of India $(11,15,25)$. However, some other Indian authors have reported a higher prevalence of XDR-TB among MDR-TB cases $(13,14)$.

\section{Conclusion}

The present study showed that younger age group particularly males were more affected with MDR-TB. Under-nutrition was quite prevalent among the MDR-TB patients. $56.7 \%$ cases were addicted to alcohol and $54.3 \%$ cases were addicted to smoking. 85.8\% patients took treatment for TB and $44.1 \%$ not completed their treatment. Relapse of previous antituberculosis treatment was found to be the major contributor of MDR-TB suspect cases in Kumaon region. Prevalence of XDR-TB was also found to be low. Overall, the findings of this study emphasize the importance of studying the socio-demographic factors and baseline clinical characteristics in different MDR-TB patient categories to timely modify and strengthen the national programs.

\section{Recommendation}

1. As young males are most commonly affected with MDR tuberculosis. Greater emphasis should be given on screening and treatment of young males, as they form the economic base of the family.

2. Proper nutritional support is the need of the hour and high percentage of patients were found to have low BMI. Awareness regarding proper nutrition and proper dietary supplements should be ensured since early adulthood, as they form bulk of patients.

3. Health education and awareness program should be conducted.

4. Strict compliance monitoring of all the patients on anti-tubercular treatment should be ensured.

5. Early diagnosis of drug resistance from all retreatment cases, quality DOTS services and more control and rational use of second-line anti-TB drugs can prevent emerging of MDR/XDR-TB as a major public health problem.

\section{Limitation of the study}

Generalizability of the findings of this study however may be limited. The study was limited to MDR-TB patients who belonged to Kumaon region and therefore was not representative of the total MDR pool in the state.

\section{Authors Contribution}

All the authors have contributed equally.

\section{References}

1. Barberis I, Bragazzi NL, Galluzzo L, Martini M. The history of tuberculosis: from the first historical records to the isolation of Koch's bacillus. J Prev Med Hyg. 2017;58(1):E9-E12. PMID: 28515626; PMCID: PMC5432783. [PubMed].

2. Alexander $P E, D e P$. The emergence of extensively drugresistant tuberculosis (TB): TB/HIV coinfection, multidrugresistant $T B$ and the resulting public healththreat from extensively drug-resistant TB, globally and in Canada. Can J Infect Dis Med Microbiol. 2007;18(5):289-91. doi: 10.11552007/986794. PMID: 1893728; PMCID: PMC2533560.[PubMed].

3. Drug-resistant tuberculosis - WHO. [Cited on 2020 Dec 4]. Available from: https://www.who.int/tb/areas-ofwork/drug-resistant-tb/en/

4. Global tuberculosis report 2019 - WHO. [Cited on 2020 Dec 8]. Available from: https://www.who.int/tb/publications/global report/en/

5. Drug-resistant TB: XDR-TB FAQ - WHO. [Cited on 2020 Dec 12]. Available from: https://www.who.int/tb/areas-ofwork/drug-resistant-tb/xdr-tb-faq/en/

6. Sharma SK, Mohan A, Kadhiravan T. HIV-TB co-infection: epidemiology, diagnosis \& management. Indian J Med Res. 2005 Apr;121(4):550-67. PMID: 15817963.[PubMed] 
INDIAN JOURNAL OF COMMUNITY HEALTH / VOL 32 / ISSUE NO 04 / OCT - DEC 2020

7. TB Alliance - Envisioning a world without TB·[Cited on 2020 Dec 22]. Available from: www.tballiance.org/

8. Prasad R, Singh A, Balasubramanian V, Gupta N. Extensively drug-resistanttuberculosis in India: Current evidence on diagnosis \& management. Indian J MedRes. 2017;145(3):271-293. doi: 10.4103/ijmr.IJMR_177_16. PMID: 28749390; PMCID: PMC5555056.[PubMed].

9. Central TB Division, Directorate General of Health Services, Ministry of Health and Family Welfare. Guidelines on programmatic management of drug resistant tuberculosis (PMDT) in India. NirmanBhavan, New Delhi: Revised National Tuberculosis Control Programme; 2012:18-29.

10. Paramasivan $\mathrm{CN}$, Venkataraman $\mathrm{P}$. Drug resistance in tuberculosis in India. Indian J Med Res. 2004 Oct;120(4):377-86. PMID: 15520487.[PubMed]

11. Ramachandran R, Nalini S, Chandrasekar V, Dave PV, Sanghvi AS, Wares F, Paramasivan CN, Narayanan PR, Sahu S, Parmar M, Chadha S, Dewan P, Chauhan LS. Surveillance of drug-resistant tuberculosis in the state of Gujarat, India. IntJ Tuberc Lung Dis. 2009;13(9):1154-60. PMID: 19723407.[PubMed].

12. Paramasivan CN, Rehman F, Wares F, Sundar Mohan N, Sundar S, Devi S, Narayanan PR. First- and second-line drug resistance patterns among previously treated tuberculosis patients in India. Int J Tuberc Lung Dis. 2010;14(2):243-6. PMID: 20074419.[PubMed].

13. Datta BS, Hassan G, Kadri SM, Qureshi W, Kamili MA, Singh H, Manzoor A, Wani MA, Shamas-u-Din, Thakur N. Multidrug-resistant and extensively drug resistant tuberculosis in Kashmir, India. J Infect Dev Ctries. 2009 Nov 21;4(1):19-23. doi: 10.3855/jidc.669. PMID: 20130374. [PubMed].

14. Udwadia ZF, Moharil G. Multidrug-resistant-tuberculosis treatment in the Indian private sector: Results from a tertiary referral private hospital in Mumbai. Lung India. 2014;31(4):336-41. doi: 10.4103/0970-2113.142101. PMID:25378840; PMCID: PMC4220314.[PubMed].

15. Dholakia YN, Shah DP. Clinical profile and treatment outcomes of drug- resistant tuberculosis before directly observed treatment strategy plus: Lessons for the program. Lung India. 2013;30(4):316-20. doi: 10.4103/09702113.120608. PMID: 24339490; PMCID: PMC3841689.[PubMed].

16. Sharma SK, Kumar S, Saha PK, George N, Arora SK, Gupta D, Singh $U$, Hanif $M$, Vashisht RP. Prevalence of multidrug-
[Tuberculosis patients...] | Awasthi S et al resistant tuberculosis among category Ilpulmonary tuberculosis patients. Indian J Med Res. 2011 Mar;133(3):312-5. PMID: 21441686; PMCID: PMC3103157.[PubMed].

17. Gupta S, Bandyopadhyay D, Gupta S, Sadhukhan S, Banerjees S. A sociodemographic study of multidrug resistant tuberculosis cases from DOTS clinics of Kolkata. J Indian Med Assoc. 2012;110(10):723-5. PMID: 23738405. [PubMed].

18. Mukherjee $\mathrm{P}$, Prasanta Ray Karmakar $\mathrm{P} R$, et al. Sociodemographic and clinical profile of multi drug resistant tuberculosis patients: a study at drug resistant tuberculosis centers of Kolkata. IOSR- J Dent Med Sci 2015; 14(8):52-8

19. Azhar GS. DOTS for TB relapse in India: A systematic review. Lung India. 2012;29(2):147-53. doi: 10.4103/09702113.95320. PMID: 22628930; PMCID: PMC3354489.[PubMed].

20. Sethi S, Mewara A, Dhatwalia SK, et al. Prevalence of multidrug resistance in Mycobacterium tuberculosis isolates from HIV seropositive and seronegative patients with pulmonary tuberculosis in north India.BMC Infectious Diseases.2013; 13:137. doi: 10.1186/1471-2334-13-137.

21. Sharma SK, Mohan A, Kadhiravan T. HIV-TB co-infection: epidemiology, diagnosis \& management. Indian J Med Res. 2005;121(4):550-67. PMID: 15817963. [PubMed].

22. World Health Organization. TB/HIV: a clinical manual. Available from: http://whqlibdoc.who.int/publicatio ns/2004/9241546344.pdf

23. Sungkanuparph S, Eampokalap B, Chottanapund S, Thongyen S, Manosuthi W. Impact of drug-resistant tuberculosis on the survival of HIV-infected patients. Int J Tuberc Lung Dis. 2007;11(3):325-30. PMID: 17352100.[PubMed].

24. World Health Organization. Global tuberculosis report 2014. [Internet] [cited 2015 May 27 ]. Available from: http://apps.who.int/iris/bitstream/10665/137094/1/9789 241564809_eng.pdf

25. Porwal C, Kaushik A, Makkar N, Banavaliker JN, Hanif M, Singla R, Bhatnagar AK, Behera D, Pande JN, Singh UB. Incidence and risk factors for extensively drug-resistant tuberculosis in Delhi region. PLoS One. 2013;8(2):e55299. doi: 10.1371/journal.pone.0055299. Epub 2013 Feb 4. PMI: 23390524; PMCID: PMC3563594.[PubMed]

\section{Tables}

TABLE 1 SOCIO-DEMOGRAPHIC PROFILE OF MDR-TB PATIENTS ( $\mathrm{N}=127$ )

\begin{tabular}{|c|c|c|c|}
\hline Parameter & Characteristics & Frequency & Percent \\
\hline \multirow[t]{5}{*}{ Age (in years) } & $11-20$ & 13 & 10.2 \\
\hline & $21-30$ & 44 & 34.5 \\
\hline & $31-40$ & 28 & 22.1 \\
\hline & $41-50$ & 23 & 18.1 \\
\hline & $>50$ & 19 & 15.1 \\
\hline \multirow[t]{2}{*}{ Sex } & Male & 94 & 74.1 \\
\hline & Female & 33 & 25.9 \\
\hline \multirow[t]{3}{*}{ Religion } & Hindu & 110 & 86.6 \\
\hline & Muslim & 15 & 11.8 \\
\hline & Others & 2 & 1.6 \\
\hline Education & Illiterate & 23 & 18.1 \\
\hline
\end{tabular}




\begin{tabular}{|c|c|c|c|}
\hline & $5^{\text {th }}$ & 45 & 35.4 \\
\hline & $10^{\text {th }}$ & 21 & 16.6 \\
\hline & Above $12^{\text {th }}$ & 38 & 29.9 \\
\hline \multirow[t]{2}{*}{ Marital status } & Married & 92 & 72.4 \\
\hline & Unmarried & 35 & 27.6 \\
\hline \multirow[t]{2}{*}{ Family type } & Nuclear & 41 & 32.3 \\
\hline & Joint & 86 & 67.7 \\
\hline \multirow[t]{2}{*}{ Residence } & Rural & 71 & 55.9 \\
\hline & Urban & 56 & 44.1 \\
\hline \multirow[t]{2}{*}{ Alcohol } & Yes & 72 & 56.7 \\
\hline & No & 55 & 43.3 \\
\hline \multirow[t]{2}{*}{ Smoking Habit } & Yes & 69 & 54.3 \\
\hline & No & 58 & 45.7 \\
\hline \multirow[t]{8}{*}{ Occupation } & Unemployed & 9 & 7.1 \\
\hline & Housewife & 23 & 18.1 \\
\hline & Labourer & 16 & 12.6 \\
\hline & Skilled worker & 19 & 15.1 \\
\hline & Service & 25 & 19.7 \\
\hline & Student & 17 & 13.4 \\
\hline & Business & 8 & 6.2 \\
\hline & Farmer & 10 & 7.8 \\
\hline
\end{tabular}

\section{TABLE 2 BASELINE CLINICAL CHARACTERISTICS OF MDR-TB PATIENTS}

\begin{tabular}{|c|c|c|c|}
\hline Parameter & Characteristics & Frequency & Percent \\
\hline \multirow[t]{2}{*}{ Site of disease } & Only pulmonary & 127 & 100 \\
\hline & Pulmonary +Extra-pulmonary & 0 & 0 \\
\hline \multirow[t]{2}{*}{ Status of drug resistance } & MDR & 122 & 96.1 \\
\hline & XDR & 5 & 3.9 \\
\hline MDR suspect category & Category A & 22 & 18.1 \\
\hline$(n=122)$ & Category B & 100 & 81.9 \\
\hline \multirow[t]{3}{*}{ HIV status } & Negative & 121 & 95.3 \\
\hline & Not known & 5 & 3.9 \\
\hline & Positive & 1 & 0.8 \\
\hline \multirow[t]{3}{*}{ Co-morbidities ( $n=25)$} & Diabetes & 21 & 84 \\
\hline & COPD & 1 & 4 \\
\hline & Others & 3 & 12 \\
\hline \multirow[t]{2}{*}{ Nutritional status } & Normal (BMI $\geq 18.5 \mathrm{~kg} / \mathrm{m} 2)$ & 31 & 24.4 \\
\hline & Undernourished $(\mathrm{BMI}<18.5 \mathrm{~kg} / \mathrm{m} 2)$ & 96 & 75.6 \\
\hline \multirow[t]{4}{*}{ Presenting symptoms* } & Cough With Expectoration & 117 & 92.1 \\
\hline & Fever & 121 & 95.3 \\
\hline & Loss Of Appetite \& Weight & 114 & 89.8 \\
\hline & Shortness Of Breath & 47 & 37.1 \\
\hline \multirow[t]{2}{*}{ Chest radiographic lesions } & Unilateral & 6 & 4.7 \\
\hline & Bilateral & 121 & 95.3 \\
\hline \multirow[t]{3}{*}{ Investigations done* } & Chest X-Ray & 124 & 97.6 \\
\hline & CBNAAT & 122 & 96.1 \\
\hline & Culture & 12 & 9.5 \\
\hline \multirow[t]{2}{*}{ History of TB T/T Taken } & Yes & 109 & 85.8 \\
\hline & No & 18 & 14.2 \\
\hline \multirow[t]{2}{*}{ TB T/T Taken ( $\mathrm{N}=109)$} & Complete & 61 & 55.9 \\
\hline & Incomplete & 48 & 44.1 \\
\hline \multirow[t]{2}{*}{ Patient outcome } & Under $\mathrm{T} / \mathrm{T}$ & 121 & 95.3 \\
\hline & Died & 6 & 4.7 \\
\hline
\end{tabular}

